\title{
Anticipar la libertad: participación psi en los procesos de criminalización de mujeres privadas de libertad en Uruguay (Anticipate the freedom: Psi participation in the processes of criminalization of women deprived of liberty in Uruguay)
}

\author{
OÑATI SOCIO-LEGAL SERIES VOLUME 10, ISSUE 1S (2020), 184S-217S: THE FOURTH WAVE OF \\ FEMINISM: FROM SOCIAL NETWORKING AND SELF-DETERMINATION TO SISTERHOOD \\ DOI LINK: HTTPS://DOI.ORG/10.35295/OSLS.IISL/0000-0000-0000-1055 \\ RECEIVED 01 FEBRUARY 2019, ACCEPTED 20 MARCH 2019
}

\section{NATALIA LAINO TOPHAM* (iD)}

\section{Resumen}

Con el propósito de comprender los procesos de evaluación pericial, a cargo de operadores psi y operadores judiciales, que transitan las mujeres privadas de libertad en Uruguay para acceder al beneficio de la libertad anticipada y cómo éstos se asocian a la construcción de su peligrosidad, se presentan cuatro ejes analíticos que configuran las prácticas psi periciales como prácticas de producción de verdad. Esta investigación se realizó con una metodología cualitativa, con entrevistas, análisis documental y observación participante. Del análisis surge una fuerte invisibilización de las mujeres en el sistema penal, la presencia del repertorio empirista (objetividad, imparcialidad, neutralidad), la presencia de la confesión y la valoración del arrepentimiento con un lugar privilegiado en las prácticas de evaluación, la contribución psi en la construcción de una biografía instalando la ficción del sujeto como determinación, y la participación psi en un marco general de control, vigilancia y gestión de las poblaciones.

\section{Palabras clave}

Mujeres privadas de libertad; tecnologías psi; evaluación pericial; libertad anticipada

\section{Abstract}

For the purpose of understanding the processes of expert assessment, carried out by psi operators and judicial operators, that women deprived of liberty get through in Uruguay to access the benefit of anticipated freedom and how they are associated with

\footnotetext{
* Licenciada en Psicología por la Facultad de Psicología, Magíster en Psicología Social por la Facultad de Psicología y Doctoranda en Psicología, Facultad de Psicología, Universidad de la República (Uruguay). Profesora Asistente del Instituto de Psicología Social de la Facultad de Psicología, Universidad de la República. Datos de contacto: Universidad de la República, Facultad de Psicología: Tristán Narvaja 1674, Montevideo, Uruguay, CP 11200. Dirección de email: nlaino@psico.edu.uy
} 
the construction of their dangerousness, four analytical axes are raised which configure the expert practices as practices of production of the truth. This research was conducted with a qualitative methodology, with interviews, documentary analysis and participant observation. The analysis reveals a strong invisibility of women in the penal system, the presence of the empiricist repertoire (objectivity, impartiality, neutrality), the presence of confession and the value of repentance with a privileged place in the evaluation practices, the psi contribution in the construction of a biography installing the fiction of the subject as a determination, and the psi participation in a general framework of control, surveillance and management of the populations.

\section{Key words}

Women deprived of liberty; psi technologies; expert evaluation; anticipated freedom 


\section{Table of contents}

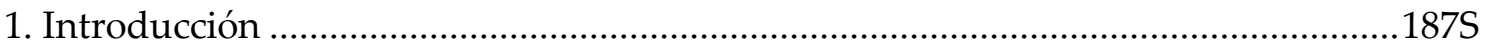

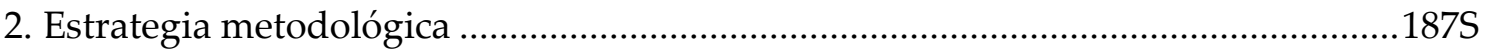

3. El lugar de las mujeres en el sistema penal uruguayo ...........................................189S

4. Producción de verdad en las prácticas de evaluación pericial ..................................191S

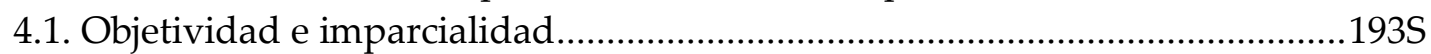

4.2. Credibilidad del relato: incompatibilidad entre las versiones.........................198S

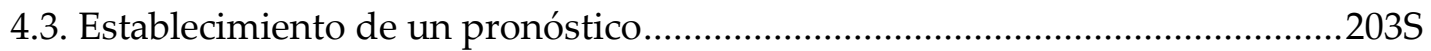

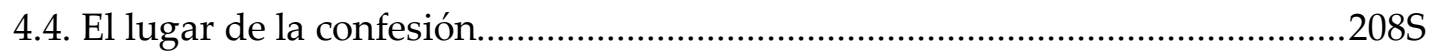

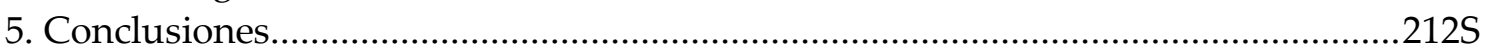

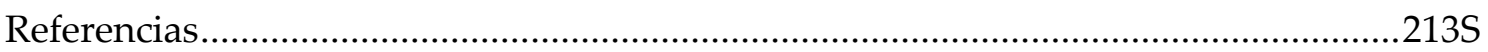




\section{Introducción}

A continuación, se presentarán los resultados de una investigación sobre los procesos de evaluación pericial, a cargo de operadores $\mathrm{psi}^{1} \mathrm{y}$ operadores judiciales, que transitan las mujeres privadas de libertad para acceder al beneficio de la libertad anticipada. Dicho estudio recoge insumos de diez años de experiencia docente universitaria en el campo de lo carcelario y surge a partir de constatar la preocupación de las propias mujeres sobre las dificultades en el acceso a la libertad anticipada, así como de visualizar el complejo entramado en el que participan los técnicos psi con discursos de poder sobre las mujeres.

En la actualidad la evaluación para la libertad anticipada continúa apoyándose fuertemente en la valoración de la peligrosidad -que justifica la medida de encierro como medida de seguridad- así como en el resguardo científico sustentado en la pretensión de objetividad, imparcialidad y no vinculación entre el informe técnico y la decisión del magistrado. A pesar de que la consideración sobre la peligrosidad ha sido ampliamente cuestionada en los últimos años (Andrés y Redondo 2007, López Gallego 2010, Mantilla 2010), su esencia continúa siendo primordial en la aplicación y mantenimiento de las medidas de seguridad en el sistema judicial. Por lo tanto, nos interesa conocer ¿qué lugar ocupamos los técnicos de las disciplinas psi en los procesos de evaluación? ¿Qué más hacemos en el intento de explicar y describir a las mujeres vinculadas a los delitos? ¿Qué lugar sostiene y construye el saber científico en el sistema jurídico penal?

Nos hemos propuesto comprender los elementos que componen las prácticas de evaluación asociadas a la construcción de la mujer delincuente como peligrosa, y visualizar los efectos que produce el discurso de la peligrosidad, así como las relaciones que se entretejen en este entramado. Para esto trabajamos en la distinción de las prácticas de evaluación pericial para el asesoramiento de la libertad anticipada, en la identificación de las posiciones enunciativas que construyen las mujeres privadas de libertad desde los contextos de evaluación técnico-profesional y en la caracterización de las prácticas jurídico-sociales en las que se inscriben los procesos de valoración de la peligrosidad para el otorgamiento de la libertad anticipada.

El artículo se organiza del siguiente modo: se presenta la estrategia metodológica utilizada, el lugar de las mujeres en el sistema penal uruguayo, la producción de verdad en las prácticas de evaluación pericial y las conclusiones.

\section{Estrategia metodológica}

Optamos por una metodología cualitativa acoplada con diversos aportes teóricometodológicos. La intuición como modo de investigación propuesta por Henri Bergson nos permite trabajar sobre la distinción de los verdaderos problemas (construcción del

\footnotetext{
${ }^{1}$ Nikolas Rose introduce la noción "psi" para referirse a un conglomerado de saberes disciplinares que incluye, al menos, la psicología, la psiquiatría y el psicoanálisis. Saberes que han dado emergencia a la comprensión de los seres humanos como seres psicológicos, difundiendo verdades sobre sus formas de pensar, de desear y de actuar. La codificación de su lenguaje se ha derramado y abarca a otros agentes como trabajadores sociales, maestros, funcionarios de prisiones, etc. que conforman una red psicologizada. De este modo las disciplinas psi, con estrategias y tecnologías específicas, han cobrado una gran capacidad para penetrar en las prácticas de conducción de la conducta y de gobierno, y han promovido un amplio repertorio para hablar, juzgar, evaluar y dar significado a la relación de los sujetos con ellos mismos.
} 
problema) de los falsos problemas (descubrimiento de las soluciones). Nos dirá Deleuze (1987, p. 12): “El problema tiene siempre la solución que merece en función de la forma en que se plantea, de las condiciones bajo las que es determinado en cuanto problema, de los medios y de los términos de que se dispone para plantearlo". Asimismo, trabajamos con una perspectiva etnometodológica y de análisis de discurso de modo de comprender cómo las prácticas discursivas configuran, mantienen y promueven relaciones de poder (Foucault 2015); y finalmente con la contribución de la reflexividad -mayoritariamente proveniente de las epistemologías feministas (Harding 1987)- y del análisis de la implicación (Lourau 1988). Ambas nos permiten problematizar sobre las relaciones que establecemos en los procesos de investigación (cuestionando la oposición sujeto-objeto), reconocer los efectos de nuestras acciones, relativizar nuestras verdades y considerar las versiones que construimos. De este modo nos dirá Harding (1987, p. 25) que "la clase, la raza, la cultura, las presuposiciones respecto al género, las creencias y los comportamientos de la investigadora, o el investigador mismo, deben ser colocados dentro del marco de la pintura que ella o él deseen pintar".

Los aportes teórico-metodológicos utilizados han contribuido con un análisis crítico de la información que nos descentra de la idea de corroborar y demostrar lo que existe para visualizar los procedimientos por los cuales producimos juegos de verdad (Foucault 1999), juegos que escenifican modos de vida y modos de existencia. En este sentido esta misma escritura no es ajena a estos procesos de producción de verdad, porque también cuando escribimos producimos nuevas redes de conexiones, nuevas formas de acoplar acontecimientos y de darles sentido.

El trabajo de campo se realizó durante el período 2013-2015 involucrando la participación de diversos actantes (Tesniére 1994): mujeres privadas de libertad en el proceso de evaluación para la libertad anticipada alojadas en la unidad no. 5 (cárcel que aloja a la mayor cantidad de mujeres de nuestro país); operadores psi (profesionales del Instituto Nacional de Criminología -INACRI-: psicólogos, psiquiatras, trabajadores sociales, encargados de asesorar sobre la libertad anticipada) y operadores judiciales (jueces penales, abogados defensores y fiscales). Los relatos, las narraciones que se tomaron para el análisis se recogieron de entrevistas semidirigidas y en profundidad, de conversaciones, de documentos: informes de pericias, informes de convivencia del establecimiento, evaluaciones de ingreso al establecimiento, reglamentos, normativas y leyes, jornadas académicas; y de las observaciones registradas en el diario de campo. Las observaciones surgen de los distintos momentos y tránsitos del proceso de investigación y de la presencia semanal en la unidad no .5 durante un año. Ese estar en la unidad posibilitó recorrerla semanalmente, mantener conversaciones con el personal, policías, equipos de dirección, mujeres privadas de libertad, diversos actores que participan en vida cotidiana del centro penitenciario, tomar mayor contacto con la dinámica del centro, con los distintos sectores de alojamiento, con las formas de gestión y toma de decisiones, con la diagramación de los espacios, la disposición del tiempo, los modos de relacionamiento y la circulación de los afectos.

El tiempo de trabajo estuvo marcado por el propio proceso de investigación y por el criterio de saturación. Para el análisis se trabajó con el software Atlas.Ti para organizar la información y trabajar con grandes volúmenes de texto, y con análisis del discurso como alternativa metodológica para el estudio de los llamados procesos sociales. 


\section{El lugar de las mujeres en el sistema penal uruguayo}

A continuación, se presentan algunas particularidades que caracterizan las condiciones del encierro que viven las mujeres privadas de libertad en Uruguay, incluyendo coincidencias con países de la región y con otras partes del mundo. Dichas particularidades nos permiten ver el lugar que ha tenido y que mantiene la mujer en los sistemas de reclusión carcelaria. Un lugar que insiste en la infantilización, en la equivalencia entre lo femenino y lo maternal, con una propuesta de tratamiento que refuerza los estereotipos de género.

Las tasas de encierro en la región han crecido considerablemente en los últimos 20 años. Particularmente en Uruguay la población privada de libertad se triplicó, aproximándose a la cifra de 11.005 a nivel nacional y con una alta tasa de prisionización, de este total aproximadamente 600 son mujeres (Petit 2017). Uruguay ha iniciado, alrededor del año 2005, un proceso de reforma penitenciaria introduciendo algunos cambios significativos: puestos de mando con perfiles profesionales, capacitación del personal, equipamiento e infraestructura, aspectos jurídicos (redención de pena por trabajo y estudio, nuevos mecanismos para solicitar la libertad anticipada y la prisión domiciliaria), ingreso de operadores civiles para el trato directo de las reclusas y los reclusos, política de clasificación y progresividad, unificación del sistema penitenciario con carácter nacional, articulación con otros actores del Estado y acuerdos de participación público-privada. Sin embargo, no se ha logrado virar el rumbo de la grave situación que atraviesa el sistema penitenciario: graves condiciones de hacinamiento -exceso de personas presas sobre la cantidad de plazas disponibles-, malas condiciones de convivencia, alimenticias, sanitarias, y de salud en su más amplio sentido.

La privación de libertad como la prisión preventiva se ha convertido en la medida utilizada por excelencia ante la sospecha de la comisión de un acto delictivo. La prisión preventiva es una medida cautelar que implica el confinamiento de la persona por un lapso de tiempo, mientras se continúa con el proceso penal que finalizará con una sentencia definitiva. Aproximadamente el $64 \%$ de las mujeres privadas de libertad se encuentran en condición de procesadas y en espera de la condena definitiva (Juanche y Palummo 2012). Vigna (2012, p. 10) identifica algunos trabajos sobre criminalidad femenina que afirman que en la actualidad el crecimiento de los arrestos femeninos no refieren tanto al comportamiento de las mujeres, sino a la precepción que tienen los actores encargados del control social.

La invisibilidad es la característica más sobresaliente del sistema. Tanto en materia criminológica, legislativa como normativa se ha privilegiado la mirada sobre las cárceles de varones soslayando que existen mujeres que se encuentran en situación de reclusión. Si bien en Uruguay este tema ha tomado mayor relevancia en los últimos años la poca visibilidad que tienen las mujeres persiste. En las conversaciones con las operadoras y los operadores observamos que cuando se referían a las personas evaluadas para la libertad anticipada siempre hacían referencia a los varones, recién las incluían cuando se les preguntaba específicamente por ellas, casi como si no existiesen en nuestro sistema penal. Asimismo, las mujeres privadas de libertad en Uruguay y en los diferentes países suelen estar ubicadas en cárceles para varones y no en establecimientos exclusivos para mujeres. 
En cuanto al tratamiento penitenciario, se refuerza una equivalencia entre lo femenino y lo maternal. Esto nos conduce a pensar, como refiere Antony (2007), en el doble castigo que recae sobre la mujer. Si tenemos en cuenta el rol social de esposa y madre que la mujer ha ocupado históricamente, podemos entender que la prisión es para la mujer doblemente estigmatizadora, no sólo transgredió el orden social cometiendo un delito, sino que además abandonó a sus hijas/os siendo así vistas como malas madres. Este sentimiento está muy presente en ellas ya que la prisión lo refuerza con otras medidas extras que de distinta manera impiden el relacionamiento con sus hijos/as. La preocupación por sus hijas/os es una de las características más notoria en las mujeres. Muchas veces no reciben sus visitas porque la familia no lo permite o porque ellas prefieren que no pasen por esa situación, lo que lleva en muchos casos al desconocimiento de su paradero, no saber cómo están o qué saben sus hijos/as sobre ellas.

Aún se agrava más en el caso de aquellas que viven con sus hijos/as menores en prisión porque la situación se vuelve una fuerte contradicción para muchas mujeres que, por una parte, quieren estar presentes en su crianza y, por otra, les genera un fuerte sentimiento de culpa que vivan en esas condiciones por un delito cometido por ellas. Sumado a esto, muchas veces se ven forzadas a tener una conducta sumisa para mantenerlos con ellas. Las mujeres embarazadas transitan una mayor situación de vulnerabilidad ya que cursan todo el embarazo en condiciones desfavorables y muchas veces son tratadas de forma discriminatoria por el personal policial y en los hospitales. Las Reglas de Bangkok (2011), que comprometen a los Estados Parte en la búsqueda de medidas alternativas a la prisión para las mujeres embarazadas o personas que sean la fuente primaria o única de los cuidados de un niño o niña, no han logrado ese propósito en nuestro país.

Ligado a la equivalencia entre lo femenino y lo maternal, la institución carcelaria las infantiliza tomando decisiones que corresponden a las mujeres, como en el caso de la visita íntima o la crianza de sus hijos/as. "Hay control respecto a las visitas conyugales, de quién recibe y de quién efectúa la visita, con pareja comprobada, que es pareja" (Folle 2011, p. 13), las mujeres cuentan con mayores condicionantes que los varones para poder concretarla, por ejemplo, a través de la exigencia de una pareja estable. Frecuentemente reciben menos visitas que los hombres y suelen ser abandonadas por sus familias con mayor frecuencia, cuando existen visitas en general son efectuadas por otras mujeres.

Los tratamientos terapéuticos quedan muchas veces ligados a la indicación farmacológica o a la atención de trastornos apreciados como nerviosos.

Mientras que, por un lado, el sistema penitenciario mantiene en el encierro a la mujer por delitos relacionados con las drogas, por el otro, no tiene empacho en prescribirlas cuando considera que ello le ayudará a preservar el orden y el equilibrio que le conviene mantener. Ello por no mencionar que, por la misma razón, tolera, si no es que participa y obtiene beneficios, del consumo y la venta de drogas entre los internos y las internas. (Azaola 2003, p. 104)

Respecto a los delitos cometidos, existen datos que permiten afirmar que un alto porcentaje de las mujeres que están procesadas por el delito de homicidio se encuentran allí por haber dado muerte a su pareja o expareja en situaciones de violencia doméstica (Viera y Mesa 2009). Por otra parte, la vinculación con el microtráfico de drogas implica 
una actividad ilícita que les permite continuar desempeñando el rol de madre, esposa y cuidadora, y existe un alto porcentaje de mujeres que quedan vinculadas a la actividad ilícita de sus parejas.

En el caso de las llamadas mulas, transportistas que trasladan drogas de un país a otro, el riesgo que corren es enorme si consideramos que, además de cumplir la condena en otro país, pueden tener graves accidentes de salud o, incluso, riesgo de vida. La situación de las mujeres extranjeras agrava en todo sentido las condiciones mencionadas anteriormente, sobre todo respecto a las visitas, las comunicaciones y la relación con las hijas/os.

En cuanto a la oferta laboral o de capacitación, las propuestas refuerzan los estereotipos que tradicionalmente se han asignado a las mujeres: coser, limpiar, cocinar, no facilitando una real inserción laboral y la independencia económica luego de la salida. Y respecto a la atención de la salud, no se cuenta con servicios de salud adecuados para las mujeres, ni sobre la atención de la salud sexual y reproductiva.

En síntesis, observamos como refiere Carlen (2005, p. 76) que "el encarcelamiento excluye incluso a las mujeres que no estaban excluidas anteriormente a su encarcelamiento, y excluye aún más a las que ya estaban excluidas socialmente".

\section{Producción de verdad en las prácticas de evaluación pericial}

La libertad anticipada es un beneficio otorgado por el órgano máximo de justicia teniendo en consideración el asesoramiento del juez de causa, de los técnicos psi del Instituto Nacional de Criminología (INACRI) -dependiente del Poder Ejecutivo- y del establecimiento carcelario. La legislación actual, aprobada en el año 2005, menciona:

Si el penado ha cumplido las dos terceras partes de la pena impuesta, la Suprema Corte de Justicia concederá la libertad anticipada. Sólo podrá negarla, por resolución fundada, en los casos en que los signos de rehabilitación del condenado no sean manifiestos. (Ley no. 17.897, art. 11, núm. 3)

Para solicitar dicho beneficio se debe estar penada/o. Del total de la población femenina sólo el 36\% se encuentra en condición de penada y del total de ese porcentaje el 59\% ha cumplido los dos tercios de la pena (Vigna 2012), por lo tanto, nos estamos refiriendo a un porcentaje muy bajo de mujeres que podría acceder a dicho beneficio. Por su parte, la Suprema Corte de Justicia (SCJ) (2014) otorgó, en el año 2013, de 1.573 expedientes recibidos en total, 554 libertades anticipadas. En el año 2014 de 847 expedientes recibidos al primero de julio, concedió 334; y de las solicitudes de mujeres de 50 tramitadas en ese período se otorgaron 26. Frente a la solicitud de la libertad anticipada se tiene en cuenta el tiempo de pena cumplido y los signos de rehabilitación de la persona penada.

... y el tema es cómo llenamos el tema de los signos manifiestos de rehabilitación. (Entrevista a operadora técnica de INACRI, Montevideo 2014)

Este último punto es el que nos interesa abordar como escenario principal de las tecnologías psi entendiéndolo como un lugar privilegiado en los procesos de punición y criminalización de las mujeres que se encuentran en prisión. El experto psi, como representante del conocimiento científico, es llamado para asesorar al magistrado sobre el proceso que la condenada cumplió desde que se encuentra en reclusión, para decir quién es y para hacer un pronóstico sobre su conducta, de modo de poder configurar un 
discurso con carácter de verdad. Como apunta Foucault (2001, p. 24) en sus trabajos con pericias médicas:

En el punto en que se encuentran la institución destinada a reglar la justicia, por una parte, y las instituciones calificadas para enunciar la verdad, por otra, en el punto más brevemente, en que se encuentran el tribunal y el sabio, donde se cruzan la institución judicial y el saber médico o científico en general, en ese punto se formulan enunciados que tienen status de discursos verdaderos, que poseen efectos judiciales considerables.

Por su parte, el saber psi construye y sostiene de modo iterativo (Derrida 1998) una serie de condiciones necesarias que debe reunir un perito, tal como se presentan en la Jornada del día del Criminólogo (2014) organizadas por INACRI:

1. Tener conciencia de su oficio y contar con especialización en la materia para poder saber cuándo se halla en el plano de la verdad, las suposiciones y el error. 2. Veracidad: evitará caer en sobre o sub estimación de las apreciaciones. 3. Imparcialidad: sin inclinarse hacia ninguna de las partes. 4. Objetividad: empleando un criterio estrictamente científico. 5. Se expresará en un estilo sencillo, sin abusar de términos que probablemente no sean conocidos por quien solicita el informe. Cuando sea necesario incluir dichos términos deberá acompañarlos de su correcta definición. (INACRI 2014)

La tarea del perito no es clara en cuanto a su definición, los técnicos se refieren a ella como: valorar el riesgo de reincidencia, las posibilidades de inserción en el afuera, y con un cierto carácter de predictibilidad. El perfil para acceder o no a la libertad anticipada surge de las entrevistas, conversaciones y documentos. Se compone de indicadores positivos:

... buena conducta, veracidad de su relato, capacidad autocrítica, gozar del beneficio de salidas transitorias, desempeño en actividades educativas y laborales, contención familiar, vivienda, proyecto de egreso concreto y realista, no consumo de sustancias psicoactivas (...). (INACRI 2014)

y de indicadores negativos:

... mala conducta, trastornos de personalidad severos que impliquen riesgos, fugas o intento de fugas, participación en motines, nula o escasa capacidad autocrítica, francas divergencias respecto al hecho de autos registrado en el expediente, no respetar las normas de convivencia, presentar dificultades en el proceso de socialización, registrar suspensión en salidas transitorias. (INACRI 2014)

Además, se agregan diversos elementos valorados y diferentes áreas a ser consideradas, que se traducirán luego en el informe pericial.

Focalizar en estos elementos conlleva una forma particular de pensamiento que inscribe lo delictivo como rasgo individual de las personas. De este modo se instala la ficción del sujeto como determinación, como instauración, olvidando así que la forma sujeto puede ser más un efecto de producción que una forma-verdad (Foucault 2015).

Estos indicadores, elementos y áreas valoradas se volcarán en el informe pericial construyendo el perfil de la persona evaluada con su correspondiente recomendación. Del análisis de los datos surge que el informe se configura con los siguientes componentes:

1. Situación procesal: incluye el delito, los antecedentes penales y el tiempo de reclusión. 
2. Historia de vida: contiene datos filiatorios, antecedentes biográficos y familiares, alfabetización, escolarización, vida laboral, así como antecedentes somáticos, psiquiátricos y psicológicos.

3. Hecho de autos y versión de la periciada: abarca aspectos de la vida delictiva, infracciones como menor y hechos de autos actual.

4. Vida en reclusión: se incorporan datos sobre la conducta, actividades y socialización, asistencia médica, social, psicológica y jurídica, educación, acceso a peculio, salidas transitorias, visitas, apoyo familiar, redes sociales, sanciones, fugas, lesiones, participación en motines y/o huelgas de hambre.

5. Planes a futuro: alude a la existencia de proyectos en el egreso.

6. Evaluación psicológica y consideraciones sociales: aquí se incluyen rasgos de personalidad, actitud, presentación, puntualización de aspectos que de alguna forma potenciaron o facilitaron el estilo de vida delictivo.

7. Conclusiones y recomendaciones: síntesis de los signos de rehabilitación, y si se recomienda acceder o no al otorgamiento de la libertad anticipada.

Este modo de visibilidad y de enunciación (Deleuze 2013) implican la inscripción del delito en términos de una individualidad, tal como nos plantea Rose (1996, p. 21) el poder de la psicología "provino inicialmente de su capacidad para organizar, simplificar y racionalizar terrenos de la individualidad y de la diferencia humana que surgieron en el transcurso de proyectos institucionales de cura, reforma, castigo".

La ausencia de soporte afectivo, las necesidades básicas insatisfechas, la falta de modelos adecuados de identificación, sumado a la ausencia de internalización de normas y valores, contribuyó a una estructuración defectuosa de su personalidad, y a una presentación fría y desafectivizada. (Informe pericial INACRI, Montevideo 2014)

De igual modo, Foucault (2001) identifica ciertas nociones en las pericias médicas -como personalidad poco estructurada o inmadurez psicológica- para visualizar la función que cumplen estos discursos: la insistencia en inscribir la infracción como rasgo individual y el pasaje "del acto a la conducta, del delito a la manera de ser" (Foucault 2001, p. 29).

A partir de las estrategias teórico-metodológicas empleadas y valorando los usos, efectos y relaciones que promueve el lenguaje, presentaremos a continuación las insistencias que emergieron en el proceso analítico de investigación respecto a las formas de producción de verdad en las que se sostienen y a la vez producen las prácticas de evaluación pericial. Dichas insistencias se presentan a modo de cuatro ejes analíticos: 4.1. Objetividad e imparcialidad, 4.2. Credibilidad del relato: incompatibilidad entre las versiones, 4.3. Establecimiento de un pronóstico y 4.4. El lugar de la confesión.

El orden de su presentación no implica la preponderancia de uno sobre otro; los cuatro ejes se articulan y dialogan entre ellos de modo tal que nos brindan elementos para un acercamiento a la producción de verdad en las prácticas de evaluación pericial.

\subsection{Objetividad e imparcialidad}

Tanto la comunidad psi como la jurídica participan en el proceso de construcción del delito y de identidades utilizando estrategias propias del repertorio empirista (Cubells 2002) que funcionará para construir la objetividad en que se sostiene su credibilidad y el valor de la justicia. Los repertorios interpretativos son empleados como recursos para construir versiones sobre los acontecimientos. Tal como lo especifica Cubells entre sus 
funciones se destacan para el caso de las prácticas psi periciales: justificación de versiones, estrategias de anticipación y mantenimiento de la credibilidad.

Entonces tenemos los hechos de autos que tú lees en el expediente lo que sí pasó, y el bloque en la pericia, la versión del periciado. (Entrevista a operadora técnica de INACRI, Montevideo, 2014)

El uso del repertorio empirista circula en el decir de los técnicos cuando presentan los hechos como si existieran de forma independiente a la intervención humana pretendiendo borrar la carga de significados implicada en los procesos de construcción de los hechos. Como expone Cubells (2002) de este modo se les atribuye a los técnicos y magistrados -"narradores de historias"- cualidades cuasidivinas. Las prácticas de evaluación pericial se sostienen, entre otras cosas, en la pretendida objetividad que da garantía y claridad al proceso, acompañada de la neutralidad de toda influencia del sujeto, así como de la metáfora dualista adentro-afuera, sujeto-objeto.

... tenés que ser muy objetivo, muy desde afuera, muy objetivo. (Entrevista a operadora técnica de INACRI, Montevideo 2013)

El uso de dicho repertorio permite visualizar la vigencia de una concepción representacionista de la modernidad donde se privilegian estrategias que colocan el criterio de validez de los conocimientos científicos por fuera de lo humano. En los informes periciales analizados se visualizan algunas precauciones para la objetividad y la imparcialidad que los operadores utilizan recurriendo a diferentes estrategias retóricas como las identificadas por Cubells, el uso del impersonal, la tercera persona del singular o las citas de autoridad:

La abajo firmante, Of. Sub. Ayte [nombre] en su calidad de Licenciada en [grado] ha procedido a entrevistar en la Unidad [número], el día [fecha] a quien dijo ser [nombre]. (Informe pericial INACRI, Montevideo, 2014)

Se ha evaluado a la Sra. [nombre]. (Informe pericial INACRI, Montevideo, 2014)

Luego de la lectura del expediente y de la entrevista mantenida con la Sra. [nombre], se considera aconsejable NO ACCEDER al beneficio solicitado. (Informe pericial INACRI, Montevideo, 2014)

Del mismo modo vemos el uso del lenguaje para marcar posiciones distintas: el enunciado de la entrevistadora se expresa de manera afirmativa (como reflejo de la realidad) pero lo que las personas evaluadas dicen, es puesto en forma de duda o desconfianza.

Quien suscribe Sub Crio. [nombre] ha procedido a entrevistar el día [fecha], en la Unidad [número] a quien dijo ser: [nombre]. (Informe pericial INACRI, Montevideo, 2014)

Finaliza primaria estando privada de libertad, según relata. (Informe pericial INACRI, Montevideo, 2014)

Por lo tanto, el conocimiento será considerado como válido cuando refleja o se corresponde con la realidad. Pero el problema es cómo accedemos a la realidad de forma independiente a nuestras construcciones tan simplemente humanas.

Vos leés el expediente, antes de hacer la entrevista, y a veces no, para no, este, no dejarte llevar por eso que leíste, y entonces venís y te das cuenta, leyendo el expediente, que la persona realmente, no, no condice con eso que hizo, lo que te relata, entonces es un 
relato falso, entonces, bueno, ya ahí, esa es una pauta de los mecanismos que él tiene también. (Entrevista a operadora técnica de INACRI, Montevideo 2014)

Dentro de las estrategias utilizadas se recurre a ciertos conceptos y categorías del conocimiento científico olvidando que los mismos "no representan a nada si no es porque nosotros hemos decidido que representaran a algo" (Ibáñez 1992, p. 248). En el siguiente fragmento vemos el uso de algunas categorías que funcionarían como representación:

Portadora de una personalidad deficitaria, frágil, inmadura, denota impulsividad con tendencia a la actuación y baja tolerancia a la frustración, potenciada por las adicciones. (Informe pericial INACRI, Montevideo 2014)

La concepción representacionista de la modernidad establece una dicotomía radical entre sujeto y objeto, promoviendo la objetividad y separando de este modo el producto y el proceso que lo produce instalando así un aparente mundo de objetos naturales. De este modo se entrelazan la idea de distancia, exterioridad, objetividad, como algo diferente a lo subjetivo, a lo personal.

... cuando matan sí, eh, no me ha tocado por suerte violaciones, pero creo que sería un delito que también, como que me tomaría, me tendría que poner a pensar y a tratar de tomar distancia para poder ser más objetiva porque creo que lo subjetivo hay como mucho también. (Entrevista a operadora técnica de INACRI, Montevideo 2014)

Tal como advierte Cubells (2002, p. 73) que la operadora reconozca lo subjetivo en una situación particular "implica rechazar la subjetividad en el resto de las situaciones, eliminando su presencia en el proceso de interpretación y valoración de las pruebas". Aceptar la creencia en la verdad, o que podemos acceder a ella con algunos procedimientos implica colocarla en una instancia superior, exterior e independiente de nosotros. Desde esta concepción, conocimiento y saber se presentan como representación de la realidad, lo que se puede conocer es un reflejo de lo que es. A partir de unas técnicas y de unos procedimientos de saber podremos conocer quién es el interno, entre otras cosas porque se supone que existe un quién es que hay que encontrar los medios adecuados para descubrirlo. En este mismo sentido dirá Rose (1996) que la psicología no puede considerarse como algo independiente, que preexiste al conocimiento y que lo que hace sea exclusivamente descubrir, sino de forma contraria construye su objeto de estudio en el mismo proceso de producción.

Le estamos informando al juez quién es el interno, si logró o no logró cambios y si es posible o sería beneficioso el beneficio o no de la libertad anticipada. (Entrevista a operadora técnica de INACRI, Montevideo 2014)

La misma idea de informar genera la ilusión de que lo que se hace es describir la realidad sobre lo informado, ocultando el proceso de producción de esa construcción. Otra de las precauciones que utilizan los técnicos para mantener la imparcialidad y la objetividad, consiste en lograr el mismo resultado en la evaluación independientemente del técnico que la realice.

Por lo general, lo que siempre se pide es algo que el técnico, el profesional, siempre tiene que compartir, es decir, el concepto de, bueno, evalúa determinada persona con los fundamentos de tu disciplina, entonces eso siempre hay que compartirlo. (Entrevista a operadora técnica de INACRI, Montevideo 2014) 
... te das cuenta de que el discurso que hizo tú lo comparas con otros informes y es como el elemento contrario, este (...), para marcar la diferencia, a ver si con eso esta vez tiene más suerte. Pensando que esto es en función de quién te toque, en qué momento, o qué técnico, qué área, ¿no? (Entrevista a operadora técnica de INACRI, Montevideo 2013)

La neutralidad y la distancia cobran un valor positivo en la evaluación, y por consiguiente el conocimiento que el técnico pueda tener de la persona es visto como algo negativo.

Y porque también depende de la cercanía. Yo trato, por ejemplo, en lo personal, de no ver demasiados de [nombre de un establecimiento], porque [nombre de un establecimiento] fue un sistema de muchísima cercanía, hasta ediliciamente nuestra oficina estaba dentro del carcelaje, y entonces eso generó, y hasta por una razón de trabajo que en su momento fue muy beneficiosa, una proximidad. (Entrevista a operadora técnica de INACRI, Montevideo 2013)

La operadora visualiza ese acercamiento, ese conocer como un obstáculo. Es como si fuera mejor informar sobre alguien a quien no se conoce que sobre alguien que resulta conocido.

Hoy, pensándolo desde la libertad anticipada, yo no sería tan objetiva, porque conozco (...), no se genera el mismo encuentro, desde el interno hacia mí tampoco, van con otro tipo de expectativa porque la relación era otra. No se perdió lo técnico, pero el acercamiento y la proximidad fue distinta, sin duda que fue distinta. (Entrevista a operadora técnica de INACRI, Montevideo 2013)

Esta idea de lo conocido nos lleva a visualizar -como veíamos antes- la pretensión de conocer algo que está dado más allá de las relaciones humanas. No obstante, cuando la técnica dice que al conocer a la persona no se genera el mismo encuentro, también reconoce que es en las relaciones dónde se producen formas de actuar, de mirarnos, y podríamos agregar de conocernos. Pero este reconocimiento queda rápidamente oculto en la pretensión de ser objetiva, porque parecería que esa relación anterior, esa forma de conocerse no es la verdadera, que existe una esencia más allá de eso, y que se necesitan ciertos procedimientos para poder conocerla. Y será el conocimiento científico quien tendrá la potestad para distinguir lo verdadero de lo falso.

También visualizamos que el conocer tiene otros sentidos en los operadores judiciales (jueces, abogados defensores, operadores jurídicos), le dan un valor positivo a la cercanía, a ese conocer. Pero positivo en tanto posibilidad de mayor acercamiento a la verdad. Por ejemplo, en la siguiente entrevista la magistrada expresa la importancia de la proximidad con los detenidos al momento de valorar una posible simulación.

Me parece importante el informe de la autoridad carcelaria, principalmente porque son los que están todos los días, todos los días con esa persona. Vos podés venir y hacer un (...) frente al psicólogo, después que uno más o menos sabe cómo es la jugada, ¿no? Podés engañar al psicólogo, al asistente que te está entrevistando, pero es difícil mantener una simulación todos los días dentro de un establecimiento carcelario. (Entrevista a magistrada, Montevideo 2014)

Si bien se cuestiona el modelo de evaluación y de alguna manera la pretendida objetividad de las pericias, frente a esta consideración se plantea la necesidad de encontrar métodos que garanticen una mayor objetividad, algo que mida más allá del 
ojo humano. También se presentan algunas objeciones sobre este modelo de evaluación y de decisión porque no parece justo ya que dependerá del técnico o de la magistrada que evalúe, la suerte que la privada de libertad pueda tener.

Es muy depende del técnico, eso es lo que veo injusto del trámite. (Entrevista a operadora técnica de INACRI, Montevideo 2014)

... es medio suerte, como parece como, no sé, es horrible pensarlo así, pero, depende con quién te tocó, visto del lado del privado, de la persona privada de libertad, ¿no? Depende con qué juez me tocó, quién me evaluó, vamos a ver la suerte que tengo. (Entrevista a operadora técnica de INACRI, Montevideo 2014)

Los test aparecen como mayor garantía para la objetividad, se presentan como los nuevos aparatos de verificación (Preciado 2013) como un-otro conjunto de discursos que puede afirmar lo que es verdadero o falso, intentando producir técnicas de medición de las diferencias y produciendo de este modo individuos.

Algunas psicólogas, psicólogos, que dicen que en la pericia también ponen técnicas, hacen técnicas, no sé, hacen test y, eso me parece como que le da otra profesionalidad al informe, además que le vas a poner tu formación, y tu, tu corriente de la psicología o de cómo vos evalúas las cosas, también le pusiste por lo menos algo más que, podés decir, 'ta, en el test esto le dio tanto'. (Entrevista a operadora técnica de INACRI, Montevideo 2014)

De este modo olvidamos que somos los humanos, nosotros mismos -en función de una serie de intereses, valores y prácticas- que los hemos creado. Entonces, ¿de qué se trata? “¿Conocer mejor la realidad tal y como es? ¡No! Conocer mejor lo que nuestras características construyen como realidad" (Ibáñez 2001, p. 35). Algunos operadores expresan cierta crítica hacia la posible solución de los test, pero lo hacen reivindicando la objetividad en otras técnicas.

Lo que quiero defender de este modelo de pericia, que es semidirigida, es que sé lo que quiero explorar, lo dejo hablar pero voy viendo por dónde. La defiendo porque puede ser tan objetiva como otra escala. (Entrevista a operadora técnica de INACRI, Montevideo 2014)

Asimismo, la formación específica y la experiencia en el ámbito se presentan como mayor garantía de objetividad, lo vemos en los siguientes pasajes de entrevistas:

... y uno en la entrevista también ve la realidad, porque también el tema de la veracidad, que es lo que la otra persona te está diciendo, ¿no? Si tú le crees, si no lo crees, bueno, eso hace a la experiencia que uno tiene. (Entrevista a operadora técnica de INACRI, Montevideo 2014)

La credibilidad del testimonio, podemos decir que, eso es un término que también, podemos decir, tiene bajo, bajo, este, indicador de credibilidad, ¿no? Alto índice o bajo índice de credibilidad, yo lo he puesto en algunos... pero no, no gusta mucho que uno ponga eso, este, porque yo me puedo basar en todo el bagaje que tengo, de, de la experiencia previa, y de todos los aportes de las distintas disciplinas, pero, de los distintos, este, aprendizajes, pero no, no gusta mucho porque ya habría que profundizar y bueno, ¿qué? ¿Cómo llegaste a eso? ¿Cómo? Uno puede, pero... (Entrevista a operadora técnica de INACRI, Montevideo 2014)

Si bien existen unos protocolos, unas técnicas, unos modelos de entrevistas, en algunas oportunidades se resuelve en los pasillos con la idea de un estereotipo conocido. A 
continuación, veremos una narración del diario de campo que recoge una conversación entre dos operadores para definir a qué sector de la unidad iría una mujer recién llegada. Uno hizo la entrevista el otro da su opinión:

-Es una sinvergüenza.

-Si ni la viste.

-Son todas terribles sinvergüenzas. Acá nada de pobrecitas, no hay que olvidarse que están acá porque son delincuentes, pobres nada.

-A mí me da cosa, uno las ve como una...

-Una mentirosa, psicopática y estafadora [lee la entrevista, en voz alta y por arriba], no, primaria absoluta no.

-Pero es la primera vez que está en la cárcel.

-Sí, en la cárcel sí, pero no es la primera vez que comete un delito.

-Ella dijo que había un tema con los cheques pero que no había pruebas.

-Eso es mentira, si no hay pruebas no te detienen, es una mentirosa. Y estas dos que vi recién terribles vendedoras de drogas. Estas eran pichis, más de lo mismo, no como esa que tiene nivel, es más inteligente y encima roba. Mirá, te voy a contar algo enfrente de la colega... [refiriéndose a mí].

Relata un episodio de hace unos pocos días donde hirieron de un balazo a un niño en un supermercado, y termina el cuento diciendo, '¡mándala para el segundo!' Creo que el efecto que se genera con esta anécdota es el de evitar sensibilizarse con 'una delincuente', utilizando una situación donde aparece un niño herido de bala para pensar dónde ubicar a una mujer que llega por estafa, propiciando de esta manera un escenario favorable para verlas a todas 'como iguales'. (Diario de campo, Montevideo, 2013)

Entonces, respecto a la búsqueda de técnicas que garanticen una mayor objetividad podríamos decir que hay distintas apreciaciones sobre el lugar de la cercanía o de la distancia al momento de la valoración. Con todo, ya sea tanto desde la proximidad como desde la distancia, finalmente lo que se pretende es alcanzar el conocimiento del sujeto $\mathrm{y}$, en definitiva, considerar quién puede decir mejor y con mayor potestad ¿quién es la persona evaluada?

Quizá el objetivo hoy no sea descubrir lo que somos, sino rechazar lo que somos. Tenemos que imaginar y construir lo que podríamos ser para librarnos de esta clase de política de doble vínculo, que es la simultánea individualización y totalización de las estructuras del poder moderno (...). Tenemos que promover nuevas formas de subjetividad a través del rechazo de esta clase de individualidad que nos ha sido impuesta por varios siglos. (Foucault 2015, p. 328)

\subsection{Credibilidad del relato: incompatibilidad entre las versiones}

En este eje analítico veremos cómo se presentan las distintas versiones, qué lugares ocupan según las posiciones que se sos-tienen ¿qué quiere decir "contradecirse" y quiénes pueden hacerlo? La idea de la contradicción nos lleva directamente a preguntarnos sobre la imagen de pensamiento que genera nuestras condiciones de posibilidad. Deleuze (2009) nos dice que nuestro pensamiento está producido fundamentalmente por una imagen dogmática, una imagen dominante del pensamiento 
occidental que se sostiene en lo verdadero como lo previo, lo que preexiste y que remite siempre una trascendencia. Es de esta imagen de pensamiento que se desprende la filosofía de la representación (modelo-copia-simulacro), y que nos impulsa a pensar de un determinado modo y de acuerdo a un orden establecido. Solemos pensar en términos de coherencia:

... si él decide no asumir durante todo su proceso que fue él el responsable, entonces tiene también que mantener lo mismo yo no hice, no generé daño porque yo no lo hice, entonces tiene que ser también coherente. (Entrevista a operadora técnica de INACRI, Montevideo 2014)

Pensamos en términos dualistas, de contradicción, o es una cosa o es la otra, hay un relato falso y uno verdadero, y será el conocimiento científico, con sus aparatos de verificación quién podrá revelar la naturaleza de ese relato. "Siempre que una multiplicidad está incluida en una estructura, su crecimiento queda compensado por una reducción de las leyes de la combinación" (Deleuze y Guattari 2010, p. 12). Podríamos decir que el conocimiento científico, desde una concepción representacionista y empirista, reduce el acontecimiento a una estructura, a una unidad. Por eso "no hay lengua madre, sino toma del poder de una lengua dominante en una multiplicidad política. La lengua se estabiliza en torno a una parroquia, a un obispado, a una capital" (Deleuze y Guattari 2010, p. 13), generando de este modo unas posiciones privilegiadas sobre las otras.

La idea de coherencia y de no-contradicción supone, como refiere Cubells (2002, p. 173) la unicidad entre el acto y el actor, "se presupone que la naturaleza del acto depende de la naturaleza de la persona". Se espera cierta coherencia en las conductas de las personas y que además se mantengan a lo largo del tiempo, por ejemplo: SI mintió en la declaración que hizo en el juzgado, ENTONCES está mintiendo en la evaluación para la libertad anticipada. Se parte de un esquema determinista que frente a una hipótesis que se confirmaría al ver la conducta anterior- se puede pensar una sola cosa, "eso ya te da una pauta del manejo que hace". Veamos este ejemplo en el fragmento completo de la entrevista:

Y sobre todo es bien interesante comparar esa declaración con la que nos hacen a nosotros en relación a los hechos. Porque yo de hecho les pregunto: ¿te hiciste cargo del hecho? Y ahí tengo respuesta, sí o no. Y ahí voy al expediente y miro a ver qué fue, entonces muchas veces tenés contradicciones, ¿ta? Y ahí entonces cuando vos encontrás ese tipo de contradicciones empezás a pensar la entrevista desde otro lado. Bueno, si esto fue una contradicción o un engaño, una mentira, ¿qué otras cosas? Entonces empezás a mirar más el detalle, este porque eso te da ya una pauta del tipo de declaración y de manejo que hace de la entrevista. (Entrevista a operadora técnica de INACRI, Montevideo 2014)

Vemos cómo la contradicción que muestran las personas evaluadas se toma como engaño o duda frente a la credibilidad de su relato. Desde esta imagen de pensamiento los actos de las personas quedan unidos al tipo de personas que son, se construye una estructura, una unidad, en este caso con la idea de personalidad. No obstante, veremos en los siguientes fragmentos de entrevista las contradicciones que tiene la misma operadora en su relato sobre la presión que siente por parte de la dirección al dar un informe negativo:

A mí en algún momento se me ha dicho que es como castigarlos por ser pobres, no, de ninguna manera (...), entonces lo tomo hasta como una cuestión y así lo he 
fundamentado, hasta de protección, porque si yo sé que esa persona vuelve a la misma situación de calle, sin trabajo, sin nada, a retomar el consumo que tenía. Y no es castigarlo, yo no lo sentí como un castigo, lo sentí aunque no lo entiendan como, bueno, por lo menos unos meses más, te queda tan poco que entre estar en la calle y estar unos meses, quédate y pasa el invierno. (Entrevista a operadora técnica de INACRI, Montevideo 2014)

En otro pasaje de la entrevista conversando sobre el tema de la seguridad y el pedido de medidas más duras dice:

Es que mientras no hagamos prevención, mientras no hagamos prevención, este, este nivel, este nivel de delincuencias se va a mantener, o sea, ¿medidas más duras? Yo creo que más duro que estar dentro de la cárcel no sé si puede haber. (Entrevista a operadora técnica de INACRI, Montevideo 2014)

Quizá el problema no sea la contradicción en sí misma, sino cómo se juega la contradicción según los lugares y las posiciones que ocupamos. El lugar que ocupan las versiones en el cortejo de los juegos del lenguaje no es ajeno a esas posiciones y a sus condiciones de posibilidad. De este modo la credibilidad del relato es un aspecto fundamental en la evaluación pericial que nos brinda elementos para visualizar cómo se lee a la persona evaluada y qué lugar ocupa su palabra.

Fue muy fuerte la sensación que sentí cuando en una conversación una de las mujeres me contaba su experiencia con un operador del poder judicial y me decía: 'Con la gente que tiene un título me di cuenta que no tengo derecho a palabra, porque soy una pichi o una malandra'. (Diario de campo, 15/04/2013)

Recordemos las palabras que le dice Gilles Deleuze a su querido amigo Michel Foucault:

En mi opinión, tú has sido el primero en enseñarnos algo fundamental, tanto en tus libros como en el campo práctico: la indignidad del hablar por los otros. Quiero decir: nos burlábamos de la representación, decíamos que estaba acabada, pero no se sacaba la consecuencia de esta conversión teórica, a saber, que la teoría exigía que la gente involucrada hablase por fin prácticamente por su cuenta. (Deleuze, en Foucault y Deleuze 1994, p. 11)

Notemos cómo se juega este hablar por los otros en el siguiente fragmento de una entrevista realizada por un operador psi a una mujer detenida (extraído del diario de campo, setiembre 2013). El encuentro que se compone está claramente definido por:

1. la diferencia de las posiciones que se ocupan:

-No me hablés bajo [le dice firmemente el técnico a la evaluada];

2. el descreimiento de la palabra de la mujer:

-¿Consumías drogas?

- No.

-¿Estás segura?

-Sí.

-No te creo nada, pero bueno.

3. la ridiculización del relato 
¿Son inocentes los dos? [se ríe] ¡Son una cosa bárbara! ¡Ay, Dios mío!

La credibilidad del relato y la simulación están íntimamente relacionadas con la pretensión de la objetividad y de la no-contradicción. La contradicción da la pauta a los técnicos de que hay algo en el relato que no es creíble. El mismo derecho otorgado al inculpado de no tener obligación de declarar en su contra, es el mismo que lo deja en un lugar perjudicial, porque ya nada de lo que diga será creíble. Desde el momento que se le da el derecho a mentir su palabra pierde credibilidad, "considero que este hecho deja a los inculpados/as en una situación de indefensión en tanto que su palabra no tiene valor, no tiene credibilidad. Así, si se declara inocente es fácil que el Tribunal dude de su palabra" (Cubells 2002, p. 74).

En las entrevistas con las mujeres privadas de libertad insistía la sensación de que, para muchas, quienes las escuchaban descreían de su palabra. Parecía como que en los distintos encuentros con los profesionales tenían que aclarar que lo que decían era cierto, aunque ellos no lo cuestionaran, presumiendo que su relato no sería creíble. Esto mismo puede generar la sensación de que se excusan, se justifican o se defienden cuando hablan. Por otra parte, esa sensación tiene un correlato con la poca credibilidad que les otorgan los técnicos y los operadores de la justicia.

Te vienen a evaluar, pero es mentira que vos sabés lo que te van a preguntar, capaz te hacen unas preguntas y ya sacaron el tipo de persona que sos, dos preguntas, como te pueden estar media hora evaluando para hacerte una, una pericia, es una pericia, ¿no?, donde sacan tu comportamiento, tu forma de actuar, tu forma de ver las cosas. (Entrevista a mujer privada de libertad, Montevideo, 2014)

En este fragmento se presume que la operadora espera que ellas se preparen para la entrevista, por lo tanto, su relato puede no ser creíble; pero también aparece cierto pensamiento mágico sobre la tarea del psicólogo ("capaz te hacen unas preguntas y ya sacaron el tipo de persona que sos"). Veremos cómo estos dos aspectos se corresponden con entrevistas a los técnicos

... de acá del INACRI, de dictámenes se avisa al establecimiento que tal día van a ir técnicos, pero se trata que no sea con mucha anticipación porque ellos preparan también la entrevista. (Entrevista a operadora técnica de INACRI, Montevideo 2014)

Depende de cada técnico, de la formación que tenga el técnico, de la experiencia que tenga el técnico y de repente yo aún puedo hacer una entrevista de 15 minutos, sí la puedo hacer, yo [dice su nombre] sí la puedo hacer, y no significa que esté mal, no significa que vaya a ser una entrevista liviana, significa que yo, en 15 minutos, de repente, tal vez, depende de la persona que tenga enfrente, depende del tipo de delito, depende del expediente que haya leído, de muchas cosas, yo ya en 15 minutos, 20, de repente puedo dictaminar, acceder o no acceder. (Entrevista a operadora técnica de INACRI, Montevideo 2014)

La corroboración del relato de la persona evaluada, como relato verdadero o relato falso, se hace con el expediente, es lo que da la pauta para considerar la credibilidad de la persona. Se instalan así dos lugares: quiénes tienen la potestad de decir lo que es verdadero, protegidos en la imparcialidad que les confiere su posición, y quienes al tener un interés de por medio deberán demostrar la credibilidad de su relato, pero... ¿podemos decir que el sistema no tiene intereses? Y ¿qué hay de la selectividad del sistema? 
Vemos a continuación distintos pasajes de entrevistas donde los operadores psi toman el expediente como el lugar de la verdad -específicamente la sentencia del magistrado/ay el relato de la persona evaluada como corroboración, o no, del mismo.

- ¿Y cómo evalúas cuando dicen algo distinto a lo que dice en el expediente o lo que llaman algunos como simulación?

-No lo evalúas, pones que tergiversa la realidad y pones lo que dice en los folios del expediente. (Entrevista a operadora técnica de INACRI, Montevideo 2014)

Está bueno ir sin leer el expediente y ahí corroboras. Y hay cosas que asumió en la denuncia. Acá conoces a la persona y después la ves en el expediente. (Entrevista a operadora técnica de INACRI, Montevideo 2014)

El expediente se puede leer antes o después, tiene sus ventajas y sus desventajas. Se hace la entrevista, se ve el delito, el vencimiento de la condena, si tiene informes previos. Después leo el expediente y confirmo. (Entrevista a operadora técnica de INACRI, Montevideo 2014)

Pero este modo de leer el expediente y de leer a la persona como corroboración o comprobación del relato, es cuestionado por algunas voces reconociendo intereses, afectaciones y posicionamientos implicados en estas lecturas.

La mayoría de los técnicos prefiere leerlo antes al expediente, y vas un poco cargado de cosas, algunos lo hacen para confirmar, con, decir bueno, preguntarle cosas puntuales a ver si te dicen la verdad, del discurso un montón de cosas, bárbaro, pero otros ya van flechados de que no, y eso ta, eso como pesa ¿viste? Mira lo que hizo ¿no? Esto es un no seguro, la entrevista queda en tercer plano, ya van a la entrevista, cinco cosas y ya saben que van a decir que no. (Entrevista a operadora técnica de INACRI, Montevideo 2014)

... muchas compañeras, se ponían mal y decían no, con este delito [se refiere a delitos sexuales] no se le puede decir que sí nunca, es como eso es algo personal ¿entendés? (Entrevista a operadora técnica de INACRI, Montevideo 2014)

Por consiguiente, asumir el hecho, reconocerlo es un elemento favorable en la evaluación. Luego que la persona pasó por un proceso jurídico-penal y hubo una sentencia que recayó sobre su persona, se asume su culpabilidad en el hecho. Asimismo, esto se recuesta en lo que admite el recurso de casación según el art. 270 del Código del Proceso Penal: "No podrán discutirse los hechos dados por probados en la sentencia, los que se tendrán por verdaderos".

... después que hubo la sentencia yo no le voy, cuando estoy con la persona no le pregunto, usted cómo fueron los hechos, es más, yo le digo, mire sobre el expediente, ya está, ya se resolvió su responsabilidad, bueno el tema es ver, si usted entendió que bueno que hubo un proceso. (Entrevista a magistrada, Montevideo, 2014)

Mencionamos antes que una de las funciones del repertorio empirista es el mantenimiento de la credibilidad. Entonces para un informe favorable será un indicador positivo que la persona asuma, que sea "sincera".

El criterio utilizado en la práctica jurídica para valorar la declaración de los implicados -falta de imparcialidad- perjudica a éstos puesto que parece ser más creíble una declaración que les incrimine en tanto no es la esperada. Efectivamente, declarar en su contra implica socavar las expectativas del sistema jurídico que, haciendo uso del sentido común, considera que los/las implicados/as tienen la intención de esconder 
información que pueda perjudicarles con la finalidad de conseguir una sentencia favorable. (Cubells 2002, p. 76)

... ellos saben, pero igual más allá que sepan, yo se los digo, pero más allá que sepan, porque les das la oportunidad para que sean sinceros, mire que yo, después voy y tengo todos los datos, tengo todo, ellos igual te mienten, porque forma parte de, ¿viste? su manera de moverse en el mundo. (Entrevista a operadora técnica de INACRI, Montevideo 2014)

Consecuentemente cuando la persona no asume su responsabilidad en el hecho su relato pierde credibilidad:

Claro, sí, porque también, este, si condice o no, si hay divergencias respecto al hecho de autos, te cuenta una historia totalmente diferente, ahí ya digo, y a veces decís ¿para qué me hizo una historia del hombre bueno? cuando él, bueno hizo esto, de repente no va a volver a delinquir o no va a volver a repetir el delito y sí cumple con las demás, no tenía necesidad de eso. (Entrevista a operadora técnica de INACRI, Montevideo 2014)

Frente a un relato que no condice con el expediente, con la sentencia, con la asunción de la culpabilidad, se relativiza la credibilidad del relato, no se puede tomar su palabra porque no condice con el relato verdadero.

Claro, sí, bueno yo, ya cuando te dicen no, no yo no lo hice, no lo hice, bueno, entonces y entonces bueno, le iba a preguntar si generó daño pero si usted no lo hizo, le haces como ese juego, a ver cómo reacciona. (Entrevista a operadora técnica de INACRI, Montevideo 2014)

Aparece la posibilidad de darle lugar al no asumir el delito ("bueno, no lo asume"), pero esto no quiere decir que no lo haya hecho ("nunca te lo va a reconocer porque de repente está asesorado legalmente"). En este caso, aunque su relato no sea condición para un informe favorable, su discurso no es creíble.

... como que hay que diferenciar también, por h o por b esa persona está este, bueno asesorada legalmente y no lo va a, no, nunca lo va a reconocer, pero bueno esa persona no significa que igualmente vaya y lo primero que haga sea delinquir ¿no? Puede no delinquir nunca más y durante todo el proceso igual lo negó. (Entrevista a operadora técnica de INACRI, Montevideo 2014)

\subsection{Establecimiento de un pronóstico}

Una parte de la tarea pericial consiste en establecer un pronóstico sobre la conducta de la persona. La idea de predecir los comportamientos también se sustenta en la relación de unicidad entre acto y persona.

Uno ve que las personas luego de la cárcel cambian la posición. Pero los jueces parecen que miden hoy lo que pasó hace 20 años. (Entrevista a operador, Montevideo 2014)

Por eso aparecerá el nivel de la reincidencia como un factor posible a atender y junto a él la valoración de la peligrosidad, noción ya caduca pero con fuerte vigencia en las valoraciones psi.

No me gusta hablar de peligrosidad pero vas viendo la posibilidad de la reincidencia.

(Entrevista a operadora técnica de INACRI, Montevideo 2013)

El uso del conector "pero" da cuenta de la cercanía entre ambos conceptos. Y a estos se le suma la noción de riesgo. 
Yo en lo personal no sabría exactamente cómo evaluar la peligrosidad, yo en lo personal no sabría cómo evaluarla, este... a mí me gusta más en lo personal y desde mi área hablar del riesgo, riesgo social en cuanto a reincidencia. (Entrevista a operadora técnica de INACRI, Montevideo 2013)

López Gallego (2010) sugiere que las disciplinas psi han sido las principales en decir algo acerca de los diagnósticos de peligrosidad, y subraya dos elementos que operan como ejes: la contemplación de los antecedentes y los estilos de vida, vinculadas a características de personalidad como impulsividad, baja tolerancia a la frustración, agresividad, etc. En los siguientes fragmentos observamos el lugar otorgado a las características de personalidad y cómo se le otorga un lugar positivo a los cambios en la conducta:

No surgen factores que hagan presuponer la existencia de trastornos de personalidad o psicopatología clínica. Actualmente impresiona como una mujer con determinada madurez y estabilidad psicoafectiva, que logra controlar sus impulsos de manera adecuada lo cual se valora positivamente en su proceso de rehabilitación psicosocial. (Informe pericial INACRI, Montevideo 2014)

Hay de repente características como impulsividad, agresividad, eh, cuenta con qué herramientas para disminuir esas características, o no reaccionar tan bruscamente. (Entrevista a operadora técnica de INACRI, Montevideo 2014)

Entonces la tarea pericial, en el marco de un encargo institucional específico, queda ligada a la posibilidad de establecer un pronóstico-predicción sobre la probabilidad de reincidencia y la valoración del proceso de rehabilitación.

... en la entrevista está implícito, la pregunta del técnico me parece que está, bueno pero ¿va a reincidir o no? (Entrevista a operadora técnica de INACRI, Montevideo 2014)

¿Cómo evaluás vos el nivel de rehabilitación? Por el nivel de reincidencia, no tenés otro elemento. Este... no hay otro. (Entrevista a operadora técnica de INACRI, Montevideo 2013)

La consideración de la reincidencia incluiría una valoración sobre la peligrosidad de la persona, actualmente suplantada por la noción de riesgo o vulnerabilidad. Es claro el pasaje de una noción a la otra y el desuso del término "peligrosidad"; sin embargo, esto no implica necesariamente nuevas formas de pensarlos. Baratta (2011) plantea que estamos aún hoy pensando con el modelo de la criminología positivista que básicamente implica una explicación acerca del comportamiento criminal que es causal. Si bien ya no se habla de peligrosidad, notemos lo que sucede cuando se reflexiona sobre esta valoración:

... de repente se estilaba poner, de repente, un alto índice de peligrosidad en función de todo lo que le venís diciendo de las características de la personalidad, las conductas, podemos, llegabas a un, un bajo índice de peligrosidad, índice medio o alto de peligrosidad, pero hoy en día ese término está en desuso (...), porque, pero este, está en desuso, sí, este, es decir, y tiene que ver también con un tema de, bueno ta no lo dejo por ahí no, este, está en desuso pero vos igual lo decís de otra manera, ¿viste? ya le estás diciendo que si ves, los factores de cambio, ahí ya le estás diciendo de alguna manera, al momento de egresar, los factores de peligrosidad se lo estás diciendo de otra manera, porque la peligrosidad está en desuso por e, también por un tema de, bueno no sé si está bien decirlo pero este. (Entrevista a operadora técnica de INACRI, Montevideo 2014) 
Como ya se adelantó anteriormente vamos observando el entretejido que se produce entre la valoración de la reincidencia, teniendo en cuenta la peligrosidad o el riesgo, ligando esto a una particular forma de pensar al sujeto en su individualidad: formas de vida, personalidad, conducta, en el marco de una concepción de rehabilitación. Entonces, peligrosidad y riesgo aparecen en las conversaciones a veces como sinónimos y a veces como sustituto uno del otro.

De una forma o de otra se vislumbra en las conversaciones con las operadoras, una cierta incomodidad al preguntar sobre la valoración de la peligrosidad. Quizá porque es en este mismo proceso de pasaje, de conceptualización, de reflexión o de problematización, donde pueden aparecer nuevas formas de mirar y de pensar respecto al tema. Quizá este momento de relevos entre un modo y otro, es lo que nos permite sacudir/lo/nos antes de que pueda institucionalizarse, cristalizarse, consolidarse. Si bien hablar de peligrosidad se asocia a algo negativo, reduccionista, mala palabra, y la valoración del riesgo aparece como una forma más elástica y de mayor apertura, veamos qué nos puede estar queriendo decir esta mudanza de la peligrosidad hacia el riesgo.

Castel (1986) ubica el pasaje de la peligrosidad al riesgo en una nueva forma de control y en una nueva gestión de las poblaciones. Este se caracteriza por: una nueva relación con el sujeto asistido, la inclusión de una mirada epidemiológica, el pasaje del técnico al gestor de políticas sanitarias y por un lugar privilegiado para las estrategias preventivas. Se produce una nueva modalidad de la vigilancia que ya no implica el control, el castigo y la corrección de un individuo, sino correlaciones estadísticas de elementos heterogéneos, es decir factores susceptibles de producir riesgos impersonales.

Un riesgo no es el resultado de un peligro concreto del que es portador un individuo o incluso un grupo determinado, sino que es un efecto de correlación de datos abstractos o factores que hacen más o menos probable la materialización de comportamientos indeseables. (Castel 1986, p. 229)

De esta manera se pueden reagrupar factores totalmente heterogéneos entre sí que ligados en un determinado conjunto alarman sobre una posible señal de riesgo.

... antecedentes penales es algo que tener en cuenta también, si fueron uno, dos, diez. $\mathrm{Si}$, para mí sí, y ta con la experiencia que he tenido es como que, la historia familiar, la contención afectiva es una de las bases para después el estilo de vida que lleves. De hecho la mayoría es o padre ausente, o la familia muy violenta, o en realidad estuvieron pero nunca hubieron límites ¿no? entonces como, sí, para mí es fundamental. (Entrevista a operadora técnica de INACRI, Montevideo 2014)

Este pasaje de la peligrosidad al riesgo nos habla de las nuevas formas de gobierno del liberalismo avanzado. Rose (1996) hablará de nuevas formas de vigilancia y de control, de figuras estadísticas, evaluaciones de rendimientos y de capacidades, en suma, de nuevas fórmulas de gestión de las poblaciones. Resuenan las palabras de Deleuze en su Post-scriptum sobre las sociedades de control (1996) cuando nos dice que "los anillos de las serpientes son aún más complicados que los orificios de una topera" (Deleuze 1996, p. 255).

Por su parte, Andrés y Redondo (2007) proponen sustituir la peligrosidad por la valoración del riesgo para la predicción de conductas violentas, resaltando su eficacia predictiva, la posibilidad de diseñar programaciones sobre la gestión del riesgo, y de 
otorgar mayor claridad y transparencia en los dictámenes técnicos. Para estos autores el riesgo:

... se basa en comprender por qué el sujeto eligió actuar violentamente en el pasado, en determinar si los factores de riesgo/protección que influyeron en su elección siguen presentes y lo estarán en el futuro, y en promocionar los factores que le pueden llevar a tomar decisiones no-violentas en tanto que estrategias alternativas de solución de conflictos. (Andrés y Redondo 2007, p. 165)

Observemos cómo se juega esto en las entrevistas con los operadores respecto a la evaluación del riesgo:

... en realidad lo que se solicita es evaluar el riesgo que hay de que vuelva a delinquir una persona ¿no? si hay riesgo de que vuelva a delinquir o no. Ehm, ¿cómo se evalúa? yo en lo personal lo que evalúo es, eh, las características de la persona, de bueno, la impulsividad, la agresividad, la baja tolerancia a la frustración, si son, si están a un gran nivel o no y si tiene herramientas o un entorno que le permita de repente disminuir un poco esas características que son las que lo llevaron a delinquir ¿no? Así como su historia, ¿no? Ta, en lo personal como más psicoanalítica me fijo mucho también en la historia infantil ¿no? que habla mucho también de su estilo de vida. (Entrevista a operadora técnica de INACRI, Montevideo 2014)

Y lo predictivo en función de variables familiares, sociales, capacitación laboral, herramientas adquiridas, redes del afuera, de la comunidad, este algún trabajo, una experiencia laboral previa y una posibilidad de inserción en el barrio, o una familia que apoye. Entonces de alguna manera uno mira desde el punto de vista social hay elementos que marcarían que no, no, no, si quiere sostener una vida afuera podría tener elementos, requiere apoyo en la mayoría de los casos, pero encontrás elementos, que te dirían o te permiten ver que... sí, está bien que salga. (Entrevista a operadora técnica de INACRI, Montevideo 2013)

¿Cómo se construye entonces la confiabilidad en el pronóstico? cuando intentamos predecir algo lo hacemos en función de unos parámetros que establecemos previamente. Aluden Andrés y Redondo (2007):

Los expertos en predicción insisten en que el primer paso para realizar predicciones objetivas, rigurosas y eficaces es definir con rigor aquello que queremos predecir. De la correcta definición del criterio a predecir, en este caso la violencia, dependerá la posibilidad de hacer de la predicción una tarea rigurosa y no un subproducto de la intuición profesional (Edens y Douglas, 2002). (Andrés y Redondo 2007, p. 159)

Y ¿no será que encontramos aquellos que estamos buscando? ¿Descubrimos lo que pretendíamos, o encontramos lo que buscábamos? Recordemos al respecto lo que nos dice Nietzsche (2009):

Si alguien esconde una cosa detrás de un matorral, después la busca de nuevo exactamente allí $\mathrm{y}$, además, la encuentra, en esa búsqueda y en ese descubrimiento no hay, pues, mucho que alabar; sin embargo, esto es lo que sucede al buscar y al encontrar la verdad dentro de la jurisdicción de la razón. Si doy la definición de mamífero y a continuación, después de examinar un camello, digo: he ahí un mamífero, no cabe duda de que con ello se ha traído a la luz una nueva verdad, pero es de un valor limitado; quiero decir, es antropomórfica de pies a cabeza y no contiene ni un solo punto que sea verdadero en sí, real y universalmente válido, prescindiendo de los hombres. (Nietzsche 2009) 
Advertimos cómo la idea de predicción y pronóstico se ensamblan con la objetividad, la imparcialidad, la distinción entre lo verdadero y lo falso, la separación del sujeto y el objeto. Nos dirá Ibáñez (2001, p. 34) que "el ojo no puede verse a sí mismo en el acto de mirar, y cuando recurre a un artefacto para verse, solo alcanza a producir la imagen de una imagen". Por eso es suficiente presentar algunas características que los especialistas hayan definido como factores de riesgo para encontrar síntomas de peligrosidad, riesgo o anomalía.

Reducimos la complejidad, el entramado, el problema, y lo colocamos en el individuo, y en todo caso en su entorno; incluir lo social queda reducido, de esta forma, a su historia de vida y a la familia como grupo de origen. Continuamos pensando en términos de entidades independientes que se relacionan pero que están muy bien definidas cada una de ellas más allá de los encuentros posibles.

Esta valoración queda así planteada como un problema individual, de personalidad y de elecciones personales. De este modo, los fundamentos de la criminología positivista continúan presentes: considerar el comportamiento delincuencial vinculado a la anormalidad individual. En el otro polo la criminología crítica reformula las interrogantes, ya no se preguntará por quién es el criminal sino por quiénes son considerados desviados, o quién es el que etiqueta y cómo lo hace. "El objeto de estudio de la criminología dejará desde entonces de ser el delincuente y empezará a serlo el de las instancias que crean y administran la delincuencia. Se pasará de estudiar la criminalidad a estudiar los procesos de criminalización" (Anitua 2010, p. 363). Tanto la criminología crítica como el movimiento de la antipsiquiatría (Cooper, Laing, Basaglia, Szasz) han cuestionado el poder de la clasificación y del tratamiento de los especialistas, discutiendo radicalmente los propios conceptos de delincuente y de enfermedad mental, porque de este modo los problemas son despolitizados reducidos siempre a lo individual.

Porque pasa y más en los hombres hay muchos que cometen delitos, salen vuelven, y bueno no entienden que, o no entienden o por las circunstancias que sean que delinquir en definitiva no es negocio. (Entrevista a magistrada, Montevideo 2014)

Por su parte, Foucault (2002) analiza la reincidencia como un efecto de la prisión más que como una cuestión de elección individual, evidenciando que la reincidencia es provocada por la propia detención. Ya que la prisión se convierte en una fábrica de delincuentes.

Las condiciones que se deparan a los detenidos liberados, los condenan fatalmente a la reincidencia: porque están bajo la vigilancia de la policía; porque tienen asignada o prohibida la residencia en determinados lugar o lugares; porque no salen de la prisión sino con un pasaporte que deben mostrar en todos los sitios adonde van y que menciona la condena que han cumplido. (Foucault 2002, p. 272)

Siguiendo este planteo, Baratta (2011) anunciaba la imposibilidad estructural de la cárcel para producir funciones positivas, siendo que por el contrario las amplifica y reproduce, asegurando y legitimando relaciones de desigualdad que refieren a la distribución del poder y de los recursos típicos del actual modo de producción capitalista. Una de las mujeres entrevistadas muestra, desde su relato, la dificultad que percibe de que la cárcel pueda producir efectos positivos: 
... y sí que la gente va a delinquir, y si se mueren de hambre en la calle más firme que van a delinquir, cuantas presas hay compañeras mías que volvieron, por rapiña, ¿y por qué? porque no te dan un trabajo, ¿por qué? Porque estuviste presa, porque yo he trabajado en FRIPUR, he trabajado en todos lados, cuidando niños, pero ¿por qué no te dan? Porque estuviste en cana. (Entrevista a mujer privada de libertad, Montevideo 2014)

Ante la imposibilidad de la prisión de producir los efectos esperados, Foucault (2002) propone un giro al problema del fracaso de la prisión y se pregunta para qué sirve, nos dice que la prisión no parecería estar destinada a suprimir las infracciones sino más bien aprovecharlas, utilizarlas, distinguirlas y hacer con ellas una adecuada distribución. Sobre el final de su gran obra Vigilar y Castigar trabaja la noción de lo carcelario para pensar en términos de red múltiple, de tejido, más que de centro del poder; y dirá que, de este modo, la prisión no se encuentra sola en su posición central "sino ligada a toda una serie de otros dispositivos carcelarios, que son en apariencia muy distintos -ya que están destinados a aliviar, a curar, a socorrer- pero que tienden todos como ella a ejercer un poder de normalización" (Foucault 2002, p. 314).

Asimismo, la criminología crítica ha tenido sus propios procesos críticos. Aller (2010) retoma la célebre expresión de Martinson en 1974, "nada funciona, todo está mal", y menciona cómo con este planteo asoman graves consecuencias, porque si bien contaba con respaldo académico, en la praxis terminaba perjudicando a las personas detenidas puesto que implicaba más pena y reclusión, y menos tratamiento.

Lleva a suponer que si nada funciona carece de sentido gastar dinero ni emplear recursos humanos en el tratamiento carcelario (...). ¿Para qué gastar en tratamientos? Visto así, concluyeron algunos que sería mejor encerrar a las personas en la prisión y tirar la llave sin hacer nada por ella. (Martinson, en Aller 2010, p. 7)

\subsection{El lugar de la confesión}

Veremos ahora el lugar de la confesión y del arrepentimiento en las prácticas de evaluación psi periciales. Reducir el problema a uno de sus elementos nos lleva directamente a la búsqueda de la causalidad, del culpable, de la unidad. Y cuando descubrimos al culpable, sólo nos resta esperar su confesión y su correspondiente arrepentimiento.

No surge ni culpa ni arrepentimiento por los daños ocasionados, es muy común en los informes, parece el Vaticano. (Entrevista a operador, Montevideo 2014)

La confesión en el derecho penal uruguayo es considerada como una circunstancia atenuante del delito. Modifica la responsabilidad criminal/penal, dando lugar a la disminución de la pena.

Quien confiesa un crimen se compromete en cierto modo a ser su autor; quiero decir que no sólo acepta la responsabilidad por el crimen, sino que funda esa aceptación en que efectivamente, lo ha cometido. En la confesión quien habla se obliga a ser lo que dice ser, se obliga a ser quien ha hecho tal o cual cosa, quien experimenta tal o cual sentimiento; y se obliga porque es verdad. (Foucault 2014, p. 26)

Y el sistema respira... la culpabilidad se individualiza, se reduce el entramado a uno de sus elementos: la delincuente. Las disciplinas psi contribuyen a la criminalización de las personas en tanto están involucradas en la producción de subjetividad y colaboran en 
los procesos de confesión, de modo que el sujeto se comprometa con una verdad acerca de lo que es. Como nos dice Foucault al acusado se le pide no solo que responda acerca de su culpabilidad sobre los delitos imputados, sino mucho más que eso, "se le exige una confesión, un examen de conciencia, una explicación de sí mismo, una aclaración de lo que él es"' (Foucault 1996, p. 158).

El autor (2014) nos plantea que la confesión está directamente vinculada con la producción de la verdad y la caracteriza a partir de cuatro aspectos. El primero implica la diferencia entre la confesión y la declaración. Lo que las diferencia es el costo de enunciación que hay en la confesión, porque reside en pasar del no decir al decir. Segundo, la confesión para ser tal tiene que ser libre, "implica que quien habla se compromete a ser lo que afirma ser y precisamente porque lo es" (Foucault 2014, p. 26). Veamos un ejemplo en las evaluaciones:

... entonces vos tenés que diferenciar si eso que te dice corresponde a lo que él está pensando o a lo que él sabe que tiene que decir para acceder al beneficio, eso es otra, otra punta también de la cosa que hace a que eso también tú lo tengas que diferenciar. El sujeto te está diciendo lo que sabe que vos querés escuchar para esto, o que le dijo el abogado, en caso que tenga abogado particular, o que le dijo el otro, o realmente desde su propia subjetividad, lo que sabe que, lo que tiene internalizado realmente. (Entrevista a operadora técnica de INACRI, Montevideo 2014)

Al respecto, afirma Zaffaroni (2012, p. 46): “Nada cambia: si los presos estudian es para delinquir mejor, si se arrepienten son simuladores, si se matan es porque son criminales, si alguien pide una tregua está simulando para contraatacar". Continuemos con el tercer punto de la confesión, quien confiesa acepta y se somete.

... si no firmas por rebeldía te ponen más. 'Dios mío', dije yo entonces, firmé. Pero lloré, lloré porque no, no esperaba tantos años. (Entrevista a mujer privada de libertad, Montevideo, 2014)

El último aspecto sobre la confesión es que la misma modifica la relación que el criminal tiene con su crimen, siendo capaz de arrepentirse.

... eso es fundamental, el reconocimiento del daño generado a otros, porque si violó, mató qué sé yo y no, no reconoce el daño, no, no lo asume con un daño a veces también, por eso decimos responsabilidad subjetiva. A veces desde lo discursivo te dicen, sí, reconozco el daño, no te dicen esas palabras, pero te dicen sí yo sé lo que le hice, es irreparable no sé, pero sabes que esa persona no te lo está diciendo desde adentro, no internalizó, la culpa. (Entrevista a operadora técnica de INACRI, Montevideo 2014)

Foucault (2014) sintetiza estas cuatro características de la confesión de la siguiente manera:

... es un acto verbal mediante el cual el sujeto plantea una afirmación sobre lo que él mismo es, se compromete con esa verdad, se pone en una relación de dependencia con respecto a otro y modifica a la vez la relación que tiene consigo mismo. (Foucault 2014, p. 27)

Cuando el acusado modifica su relación con el crimen vemos la posibilidad de su arrepentimiento, y esto se vincula con lo que los técnicos consideran como responsabilidad subjetiva. 
Hay un punto en la entrevista que es importante, el grado de responsabilidad subjetiva que haya tenido, que tenga la persona en el momento de la entrevista, en cuanto al daño que le hizo a la víctima. (Entrevista a operadora técnica de INACRI, Montevideo 2014)

La valoración científica cobra peso en lo que respecta a la determinación psicológica porque el individuo "aparecerá tanto más responsable de su acto cuanto más ligado esté con él por una determinación psicológica. Cuanto más psicológicamente determinado esté un acto, mejor podrá su autor ser considerado un sujeto penalmente responsable" (Foucault 1996, p. 168). A pesar de lo expuesto, algunos técnicos difieren con esta valoración:

Acá hay técnicos que ponen no se arrepiente, y uno va otra vez y la persona no asume el delito, entonces cómo se va a arrepentir sino asume el delito. Hay dos palabras que en mis informes no vas a ver nunca, ni arrepentimiento, ni peligrosidad. (Entrevista a operadora técnica de INACRI, Montevideo 2014)

También en los informes periciales surge claramente el lugar del arrepentimiento y de la responsabilidad subjetiva:

La PPL [persona privada de libertad] intenta minimizar las causas de su delito justificando su conducta aduciendo que estaba drogada. No surge responsabilidad acerca del hecho cometido ni arrepentimiento.

Mantiene su negativa de los hechos pero agrega sentirse culpable por facilitar la situación, yo planifiqué ir a robar por verme ahogada, no ir a matar (...). Consideramos que la interna no logra una autocrítica de los hechos, no reconociendo su autoría en el homicidio, trasladando la responsabilidad a un tercero que no fue procesado y minimizando su responsabilidad.

En relación a los hechos mantiene una actitud no crítica, manteniendo un relato reiterativo que ha ideado negando su autoría de un homicidio, desafectivizado, no empatía hacia la víctima. Minimizando lo ocurrido y trasladando a terceros la responsabilidad.

En situación de entrevista no logra reflexionar acerca de su accionar, no reconoce daño generado a terceros. No se observan indicadores de responsabilidad subjetiva.

$\mathrm{Al}$ momento actual, la periciada asume su responsabilidad en el delito imputado, logra reflexionar sobre su conducta delictiva, atribuyendo la misma a etapa de inmadurez, como así también a la vinculación con pares infractores, hecho que actualmente cuestiona.

Hay un tema de estigma. La sociedad tiene un problema, a los uruguayos nos encanta poner a todo el mundo en la prisión. Sus colegas no quieren admitir, pero quieren que se arrodillen, que pidan disculpas a sus víctimas. (Entrevista a operador, Montevideo 2014)

Anteriormente distinguimos cómo se articulaba la confesión y el arrepentimiento con la responsabilidad subjetiva. Paternain (2013, p. 121) se formula la siguiente pregunta: "¿[S]e castiga por la responsabilidad del sujeto o para que asuma subjetivamente su responsabilidad y de esa manera se transforme en un nuevo sujeto?" Retomemos el análisis de Rose (1996) sobre las nuevas formas de gobierno impulsadas por el neoliberalismo donde la relación del sujeto consigo mismo conlleva aspiraciones de autorresponsabilidad (gestión del riesgo): 
Estos programas neoliberales, que responden a los que sufren como si fuesen los autores de su propia desgracia (...) los individuos desfavorecidos han llegado a ser considerados potencial e individualmente como agentes activos en la construcción de su propia existencia. Aquellos sujetos excluidos de los beneficios de una vida de elección, y autorrealización ya no son ahora simplemente el soporte pasivo de un conjunto de determinaciones sociales, sino que son gentes cuyas aspiraciones de autorresponsabilidad y autorrealización han sido deformadas por la dependencia cultural. (Rose 1996, p. 39)

Esta construcción activa de la propia existencia (autorresponsabilidad) promovida por el neoliberalismo encuentra un eco en las entrevistas con los técnicos:

A mí me gustaría pretender que el privado de libertad acceda al proceso de rehabilitación ¿viste? Y que después bueno, no, no vuelva más a estar preso, que a la hora de decidir de razonar, bueno de elegir el camino, que elija el camino de la no, del no delito. (Entrevista a operadora técnica de INACRI, Montevideo 2014)

... ya sea por motivos religiosos o lo que sea, la persona tiene, ya sea, la religión que tenga o crea, no sé en el mosquito, que bueno que ha encontrado determinada fuerza o fe en algo, que le ha permitido tener trabajo, fuera del establecimiento carcelario, rehacer sus vínculos familiares, entonces entender que su conducta en su momentos estuvo mal y que por eso está, está preso, y sobre él recayó una sentencia, y entonces me parece que en esos casos una rehabilitación de la persona, debe entender de que, bueno, que el delinquir no puede ser una manera de vivir, porque digo, hay un momento que, bueno, si ojalá a todos los presos les pueda llegar ese clic, que bueno que hay otras opciones de ganarse la vida. (Entrevista a magistrada, Montevideo 2014)

Garay (2001) trabaja críticamente sobre la idea de una responsabilidad vacía contrastando la pretensión de ser activamente responsable (construcción de subjetividad contemporánea: convertirnos en expertos de nosotros mismos) con la presión de que seamos productivos a un sistema, "las personas debemos ser un yo activamente responsable, debemos cumplir nuestras obligaciones no a través de relaciones dependencia y obligación de unos para con otros, sino a través del 'realízate a ti mismo'" (Garay 2001, p. 161).

Trabajando con los internos dentro del establecimiento en general te dicen yo te estudio, yo te trabajo, por qué no accedo a esto si yo te estudio y te trabajo. Y es como que ellos toman que estudian o trabajan para el otro, es esto de que, en realidad no trabaja que se apropian de las cosas ¿no? Entonces llega un momento que ellos están haciendo algo para cumplir con, y no porque consideren que a ellos les sirve. (Entrevista a operadora técnica de INACRI, Montevideo 2014)

Se visualiza una apuesta a la construcción de una realización personal puesta en este caso en el estudio y/o en el trabajo. Se trata de una racionalidad de gobierno que gobierna a través de la libertad y de la autonomía. Así, la idea de responsabilidad personal se va articulando con una cierta concepción de rehabilitación. Es la persona, a nivel individual, agente activo en la construcción de su propia existencia.

Es decir, muchas veces el interno logra, es como un proceso de evolución en su proceso de rehabilitación que logra esos avances, que logra que bueno que ya no sea necesario tener la tutela (...) después bueno ya pasa a que, bueno su comportamiento, llega en hora, es puntual, nunca intentó ingresar drogas, por ponerte un ejemplo, entonces cumplió todo su proceso de salidas transitorias bien sin ningún inconveniente, bueno 
puede solicitar salir bajo declaración jurada, él mismo se hace cargo es su responsabilidad. (Entrevista a operadora técnica de INACRI, Montevideo 2014)

La prisión como institución total (Goffman 2004) y como medida de castigo refuerza la individualidad y generaliza a la persona a partir de un acto. De este modo el problema queda puesto en el individuo, no en la sociedad, no en las prácticas. Y esto también se refuerza desde las prácticas de evaluación pericial.

Entonces después cuando tú les preguntas que hablen, se sienten víctimas de un sistema, entonces fueron los jueces, o fue la policía, o fueron los testigos, o fueron todo falla. Porque sienten que no hicieron eso. (Entrevista a operadora técnica de INACRI, Montevideo 2014)

La culpabilización funciona como uno de los mecanismos de la subjetividad capitalística (Guattari y Rolnik 2013, p. 18) y lo hace a partir de una imagen de referencia y es en función de ella, que la persona muchas veces terminará "reivindicando un territorio en el edificio de las identidades reconocidas". Foucault (2015, p. 334) ya en su última etapa de trabajo, advierte que el poder actúa sobre acciones, una acción sobre otra acción, "el ejercicio del poder consiste en conducir conductas y en disponer la probabilidad. El poder, en el fondo, es menos del orden del enfrentamiento entre dos adversarios, o del compromiso del uno respecto del otro, que del orden del gobierno". En este sentido el gobierno será la forma de dirigir las acciones de grupos o individuos y su orientación sobre las acciones de los otros.

¿Qué cosas ha logrado? ¿Ha habido cambio? ¿Está posicionado distinto? ¿Se ve distinto? ¿Ve el delito distinto? ¿Uno ve [con énfasis] que tenga un mínimo de proyecto que paute un cambio en ese estilo? ¿Tiene posibilidades de concretarlo? (Entrevista a operadora técnica de INACRI, Montevideo 2014)

\section{Conclusiones}

Nos hemos preguntado en el inicio de este trabajo: ¿Cómo se justifica el encierro de las mujeres encarceladas? ¿Cómo son tratadas? ¿Cómo son intervenidas? ¿Cómo son pensadas?, poniendo especial interés en la mirada de los técnicos, de quienes las evalúan, y de los operadores judiciales que toman decisiones acerca de su futuro. Podemos decir que las prácticas de evaluación pericial y las prácticas socio-jurídicas en las que se sostienen los procesos de valoración para la libertad anticipada (como técnicas disciplinarias, biopolíticas y gubernamentales) producen formas de verdad productivas, en tanto son generadoras de individualidad y están involucradas en la producción de subjetividad. Estas prácticas se sostienen y componen-producen a su vez una forma de verdad, sostenida en una imagen pensamiento dogmática, hegemónica, representacionista y empirista. Esto es, la pretensión de la objetividad en la tarea pericial, procurando la imparcialidad, neutralidad y separación del sujeto que conoce con el objeto a conocer. Asimismo, las relaciones de evaluación (entre evaluadora y evaluada) se caracterizan por la duda y la desconfianza sobre la palabra de la mujer privada de libertad.

El relato jurídico (ubicando el hecho expediente) se establece como relato verdadero; por lo tanto, las versiones de las mujeres evaluadas serán consideradas como válidas siempre y cuando condigan con el expediente. De este modo la tarea del técnico psi queda vinculada a descubrir o diferenciar entre la verdad-mentira de lo relatado. De ahí que 
los criterios de no contradicción y coherencia tendrán un lugar privilegiado para analizar el relato de la inculpada, aun cuando eso no siempre funciona como procedimiento general para considerar la veracidad de nuestros relatos.

Por otra parte, desde el momento que la condenada no tiene obligación de decir la verdad, nada de lo que diga será creíble; se produce así un efecto casi de desaparición de los sujetos. De este modo, la confesión (asumir el hecho o ser "responsable subjetivamente") consigue un lugar privilegiado en las prácticas de evaluación pericial, porque es mediante ese acto que la persona se vincula con la verdad, en tanto es a través de ella que afirma una verdad sobre sí misma y será en función de ella que se relacionará con un posible-futuro lugar de delincuente.

Precisamente, se va construyendo una biografía, hay alguien a quien conocer (más allá de su acto) y hay alguien que puede conocerlo, que pude descubrir una verdad en torno a esa persona. El lugar de lo biográfico adquiere un lugar fundamental en la penalidad que hará existir a la criminal antes de su crimen. Se instala la ficción del sujeto como determinación, como instauración, olvidando así que la forma-sujeto es un efecto de producción más que una forma-verdad (Foucault 1983). De este modo el lugar de la rehabilitación quedará vinculado a la medición de la reincidencia. Será posible rehabilitarse siempre que esto implique un cambio en la persona, pero no en tanto transformación que cuestiona la producción de los sujetos, los modos en que hemos sido objetivados, construidos, producidos para devenir otros; sino en tanto corrección y asunción de la autorresponsabilidad para asumir su individualidad y su existencia como delincuente.

La técnica disciplinaria trabaja de este modo en el pasaje de la infractora a la delincuente, es decir, construye una figura. A continuación de esto se instala fuertemente la polarización del ellos y nosotros, la sociedad y el delincuente, así como el cuidado de uno sobre el otro. Esto sucede en un marco más general de control, vigilancia y gestión de las poblaciones.

\section{Referencias}

Aller, G., 2010. Paradigmas de la criminología contemporánea. Conferencias, Congreso de Derecho Penal del Bicentenario de la Argentina (UBA) [en línea], 27. Buenos Aires. Disponible en: https://publicaciones.fder.edu.uy/index.php/idp/article/view/40/34 [Con acceso el 22 de marzo de 2019].

Andrés, A., y Redondo, S., 2007. Predicción de la violencia: entre la peligrosidad y la valoración del riesgo de violencia. Papeles del psicólogo [en línea], 28(3), 157-173. Disponible en: http://www.papelesdelpsicologo.es/pdf/1500.pdf [Con acceso el 22 de marzo de 2019].

Anitua, G., 2010. Historia de los pensamientos criminológicos. Buenos Aires: Editores del Puerto.

Antony, C., 2007. Mujeres invisibles: Las cárceles femeninas en América Latina. Nueva Sociedad [en línea], nํ. 208, 73-85. Disponible en:

http://nuso.org/media/articles/downloads/3418 1.pdf [Con acceso el 22 de marzo de 2019]. 
Azaola, E., 2003. Género y justicia penal en México. En: Comisión de Derechos Humanos del Distrito Federal, Comisión Mexicana de Defensa y Promoción de los Derechos Humanos (A.C.) y Fundación para el Debido Proceso Legal, eds., Violencia contra las mujeres privadas de libertad en América Latina. Ciudad de México: Corunda, 86-108.

Baratta, A., 2011. Criminología crítica y crítica del derecho penal. Trad.: Á. Búnster. Buenos Aires: Siglo XXI.

Carlen, P., 2005. Encarcelamiento de mujeres y reintegración: ¿términos contradictorios? En: M. Cruells y N. Igareda, eds., Mujeres, integración y prisión. Barcelona: Surt, 75-77.

Castel, R., 1986. De la peligrosidad al riesgo. En: F. Álvarez-Uría y J. Varela, eds., Materiales de sociología crítica. Madrid: La Piqueta, 219-243.

Cubells, J., 2002. Construcción social del delito [en línea]. Tesis doctoral, Universitat Autònoma de Barcelona, Área de Psicología Social. Disponible en: https://www.tdx.cat/bitstream/handle/10803/5425/ecs1de5.pdf [Con acceso el 22 de marzo de 2019].

Deleuze, G., 1987. El Bergsonismo. Trad.: L. Ferrero Carracedo. Madrid: Cátedra, col. Teorema.

Deleuze, G., 1996. Post-scriptum sobre las sociedades de control. En: G. Deleuze, Conversaciones. Trad.: J.L. Pardo Torío. Valencia: Pre-textos, 247-255.

Deleuze, G., 2009. Diferencia y repetición. Trad.: M.S. Delpy, H. Beccacece. Buenos Aires: Amorrortu.

Deleuze, G., 2013. El Saber: Curso sobre Foucault. (Tomo I). Trad.: P. Ires y S. Puente. Buenos Aires: Cactus.

Deleuze, G., y Guattari, F., 2010. Mil mesetas: Capitalismo y esquizofrenia. Trad.: J. Pérez Vázquez, U. Larraceta. $3^{\underline{a}}$ ed. Valencia: Pre-textos.

Derrida, J., 1998. Márgenes de la Filosofía. Madrid: Cátedra.

Folle, M., (con: N. Laino, C. Montes y M. Rodríguez), 2011. Situación de las mujeres privadas de libertad en el interior del país, en particular en los departamentos de Colonia, Durazno y Florida [en línea]. Montevideo: Proyecto Conjunto L/Oficina Planeamiento y Presupuesto/ONU-Mujeres. Disponible en: https://encuentrosenabril.files.wordpress.com/2016/04/folle-m-a-laino-n-montesc-rodrc3adguez-m-2011-situacic3b3n-de-las-mujeres-privadas-de-libertad-en-elinterior-del-pac3ads-colonia-durazno-y-florida.pdf [Con acceso el 22 de marzo de 2019].

Foucault, M., 1994. Un diálogo sobre el poder y otras conversaciones. En: M. Foucault, Poderes y estrategias. Trad.: M. Morey. Barcelona: Altaya, 7-19.

Foucault, M., 1996. La evolución de la noción del individuo peligroso en la psiquiatría legal. En: M. Foucault, La vida de los hombres infames. La Plata: Caronte, 157-177. 
Foucault, M., 1999. La ética del cuidado de sí como práctica de libertad. En: M.

Foucault, Estética, ética y hermenéutica. Obras esenciales (vol. III). Barcelona: Paidós básica, 393-415.

Foucault, M., 2001. Los anormales. Curso en el Collége de France: 1974-1975. Buenos Aires: Fondo de Cultura Económica de Argentina.

Foucault, M., 2002. Vigilar y castigar: Nacimiento de la prisión. Buenos Aires: Siglo XXI.

Foucault, M., 2014. Obrar mal, decir la verdad: La función de la confesión en la justicia. Trad.: H. Pons. Buenos Aires: Siglo XXI.

Foucault, M., 2015. El sujeto y el poder. En: M. Foucault, La ética del pensamiento: para una crítica de lo que somos. Madrid: Biblioteca Nueva, 317-341.

Garay, A., 2001. Poder y subjetividad. Un discurso vivo [en línea]. Tesis de doctorado. Universitat Autònoma de Barcelona, Facultat de Psicologia, Unitat de Psicologia Social, Departament de Psicologia de la Salut i Psicologia Social. Disponible en: https://www.tdx.cat/bitstream/handle/10803/5417/aigu1de2.pdf [Con acceso el 22 de marzo de 2019].

Goffman, E., 2004. Internados: Ensayo sobre la situación social de los enfermos. Buenos Aires: Amorrortu.

Guattari, F., y Rolnik, S., 2013. Micropolítica: Cartografías del deseo. Buenos Aires: Tinta Limón.

Harding, S., 1987. ¿Existe un método feminista? Trad.: G.E. Bernal [en línea]. Disponible en: http://pdfhumanidades.com/sites/default/files/apuntes/33\%20-

$\% 20$ Harding.\%20Existe un metodo feminista.pdf [Con acceso el 22 de marzo de 2019].

Ibáñez, T., 1992. ¿Cómo se puede no ser construccionista hoy en día? Revista de Psicoterapia, 3(12), 245-257.

Ibáñez, T., 2001. ¿Fondear en la objetividad o navegar hacia el placer? Athenea digital [en línea], $\mathrm{n}^{\circ}$. 0, 31-37. Disponible en:

http://www.raco.cat/index.php/Athenea/article/viewFile/34075/351688 [Con acceso el 22 de marzo de 2019].

Instituto Nacional de Crimonología, 2014. Evolución de las libertades anticipadas entre los años 2010 al 2014. Montevideo: Centro Nacional de Dictámenes Criminológicos, INACRI.

Juanche, A., y Palummo, J., eds., 2012. Hacia una política de Estado en privación de libertad: Diálogo, recomendaciones y propuestas [en línea]. Montevideo: SERPAJ/Observatorio del Sistema Judicial. Disponible en:

https://es.slideshare.net/JavierPalummo/palummo-hacia-una-politica-de-estadoen-privacion-de-libertad [Con acceso el 22 de marzo de 2019].

Ley №. 17.897. Libertad provisional y anticipada. Diario oficial [en línea], nº . 26835, del 19 de septiembre de 2005. Disponible en:

https://legislativo.parlamento.gub.uy/temporales/leytemp564537.htm [Con acceso el 22 de marzo de 2019]. 
López Gallego, L., 2010. Una apuesta analítica del funcionamiento del dispositivo psi pericial en el campo penal. Psicologia E Sociedade [en línea], 22(2), 396-404.

Disponible en: $\underline{\text { http://dx.doi.org/10.1590/S0102-71822010000200021 [Con acceso el }}$ 22 de marzo de 2019].

Lourau, R., 1988. El análisis institucional. Trad.: N. Fiorito de Labrune. Buenos Aires: Amorrortu.

Mantilla, M.J., 2010. “Riesgo", “peligrosidad” e "implicación subjetiva”: un análisis de las decisiones de internación psiquiátrica en la ciudad de Buenos Aires. Interface Comunicação, Saúde e Educação [en línea], 14(32), 115-126. Disponible en:

https://www.scielosp.org/article/icse/2010.v14n32/115-126/ [Con acceso el 22 de marzo de 2019].

Nietzsche, F., 2009. Sobre verdad y mentira en sentido extramoral. Traducción y notas: S. Royo Hernández [en línea]. Disponible en:

http://www.lacavernadeplaton.com/articulosbis/verdadymentira.htm [Con acceso el 22 de marzo de 2019].

Paternain, R., 2013. Los laberintos de la responsabilidad. En: C. González et al., eds., Los sentidos del castigo: El debate uruguayo sobre la responsabilidad en la infracción adolescente. Montevideo: Trilce/CSIC, 121-140.

Petit, J.M., 2017. Informe anual 2017 [en línea]. Montevideo: Comisionado Parlamentario Penitenciario. Abril. Disponible en:

https://parlamento.gub.uy/sites/default/files/DocumentosCPP/Informe\%20Anual \%202017.pdf [Con acceso el 22 de marzo de 2019].

Preciado, B., 2013. ¿La muerte de la clínica? [en línea]. Audio. Museo Nacional de Arte Reina Sofía, 9 de marzo. Disponible en:

http://www.museoreinasofia.es/multimedia/muerte-clinica [Con acceso el $22 \mathrm{de}$ marzo de 2019].

Reglas de las Naciones Unidas para el tratamiento de las reclusas y medidas no privativas de la libertad para las mujeres delincuentes (Reglas de Bangkok). Resolución aprobada por la Asamblea General de Naciones Unidas (A/RES/65/229) [en línea]. Asamblea General de la ONU, 16 de marzo de 2011. Disponible en:

https://www.unodc.org/documents/justice-and-prisonreform/Bangkok Rules ESP 24032015.pdf [Con acceso el 22 de marzo de 2019].

Rose, N., 1996. Una historia crítica de la psicología. Trad.: S. de Luca y M.C. Marchesi [en línea]. Disponible en:

http://www.elseminario.com.ar/biblioteca/Rose Una\%20historia\%20critica\%20de \%20la\%20psicologia.pdf [Con acceso el 22 de marzo de 2019].

Suprema Corte de Justicia de Uruguay, 2014. Estadísticas 2013. Montevideo: SCJ, sección Libertades y Visitas de Cárceles. Actualizado al $1^{\circ}$ de julio.

Tesnière, L., 1994. Elementos de sintaxis estructural. Madrid: Gredos.

Viera, M., y Mesa, S., 2009. Mujeres víctimas de violencia doméstica procesadas por homicidio del agresor. En: S. Rostagnol, ed., No era un gran amor: 4 investigaciones 
sobre violencia doméstica. Montevideo: Instituto Nacional de las Mujeres - Mides, $27-63$.

Vigna, A., 2012. Análisis de datos del I Censo Nacional de Reclusos, desde una perspectiva de Género y Derechos Humanos. Informe final [en línea]. Montevideo. Agosto.

Disponible en:

http://www.inmujeres.gub.uy/innovaportal/file/24956/1/infocenso.pdf [Con acceso el 22 de marzo de 2019].

Zaffaroni, E., 2012. La cuestión criminal. Buenos Aires: Planeta. 